\title{
Novel Polymers Containing Discrete Conjugated Units, Produced by the Heck Reaction
}

\author{
Sergei Fomine, Lioudmila Fomina, Héctor Quiroz FloRentino, \\ Juan Manuel Mendez, and Takeshi Ogawa \\ Instituto de Investigaciones en Materiales, Universidad Nacional Autonoma de Mexico, \\ Apartado Postal 70-360, Coyoacon, Mexico DF, 04510
}

(Received April 24, 1995)

\begin{abstract}
Novel monomers and polymers containing arylenevinylideneethynylene groups were synthesized via the Heck reaction. The polymers were amorphous and soluble in common organic solvents. They showed $T_{\mathrm{g}}$ around $60^{\circ} \mathrm{C}$ and $5 \%$ weight loss in the region of $240-340^{\circ} \mathrm{C}$ and underwent thermal cross-linking on heating to $170-190^{\circ} \mathrm{C}$ at the expense of triple bonds. One of the polymers showed strong blue luminescence with emission maxima around $380-390$ and $470-480 \mathrm{~nm}$ with excitation at $320 \mathrm{~nm}$. All polymers showed nonlinear optical susceptibility of the third order $\left(\chi^{(3)}\right)$ around $10^{-10}$ esu.
\end{abstract}

KEY WORDS Heck Reaction / Acetylenes / Luminescent Polymers /

The main chain conjugated polymers have attracted attention as materials for nonlinear optical applications. ${ }^{1}$ Poly(aryleneethynylene)s, in particular, have received considerable attention due to their relatively large third order harmonic generation, $\left(\chi^{(3)}=4.7 \times 10^{-11}\right.$ esu) and fluorescent properties. ${ }^{2-5}$ They can be readily prepared by $\mathrm{Pd}$-catalyzed coupling of bis-arylhalides with terminal bis-acetylenes. The processing of poly(aryleneethynylene)s into films and fibers is crucial for the development of these materials. However, poly(arylenethynylene)s are usually insoluble and infusible due to polarizable $\pi$-electrons and rigid polymer chains. Improvement of processability of conjugated polymers has been attempted by incorporation of long aliphatic tails as side chains of poly(aryleneethynylene). ${ }^{3-5}$ A soluble, high molecular weight dendritic poly(aryleneethynylene) has been synthesized by the Heck condensation of 4-ethynyl- $\beta, \beta$-dibromostyrene. ${ }^{6}$ However, the incorporation of bulky side groups often leads to decrease in conjugation because of sterical hindrance due to the presence of bulky side groups in the polymer chain. Thus, even high molecular weight poly(aryleneethynylene)s $\left(M_{w}=10^{5}\right)$ often showed absorption maxima in the visible region at around $400 \mathrm{~nm}$ which reflects only moderate conjugation. ${ }^{4}$ Poly(4-ethyl- $\beta, \beta$-dibromostyrene) ${ }^{6}$ show an absorption maximum at around $400 \mathrm{~nm}$ where the corresponding model compound, 4,4'-bis$[(\beta, \beta$-diethynylphenyl)vinyl $]$ diphenyldiacetylene), showed an absorption maximum in the same region. This means that no conjugation exists between repeating units in the polymers due to sterical hindrance in branched macromolecules. Bearing this in mind, it is reasonable to suggest that a polymer consisting of discrete aryleneethynylene moieties linked together by flexible spacers should exhibit $\chi^{(3)}$ values of the order of those showed by conventional poly(aryleneethynylene)s. Thus, polymers containing fluorescein moieties incorporated into a polymer chain showed $\chi^{(3)}$ as high as $2 \times 10^{-10}$ esu with an excellent transparency. ${ }^{7}$

This work is concerned with the synthesis of some novel polymers by the Heck reaction of dibromides of rigid and conjugated arylene- 
S. Fomine et al.

Monomer Synthesis

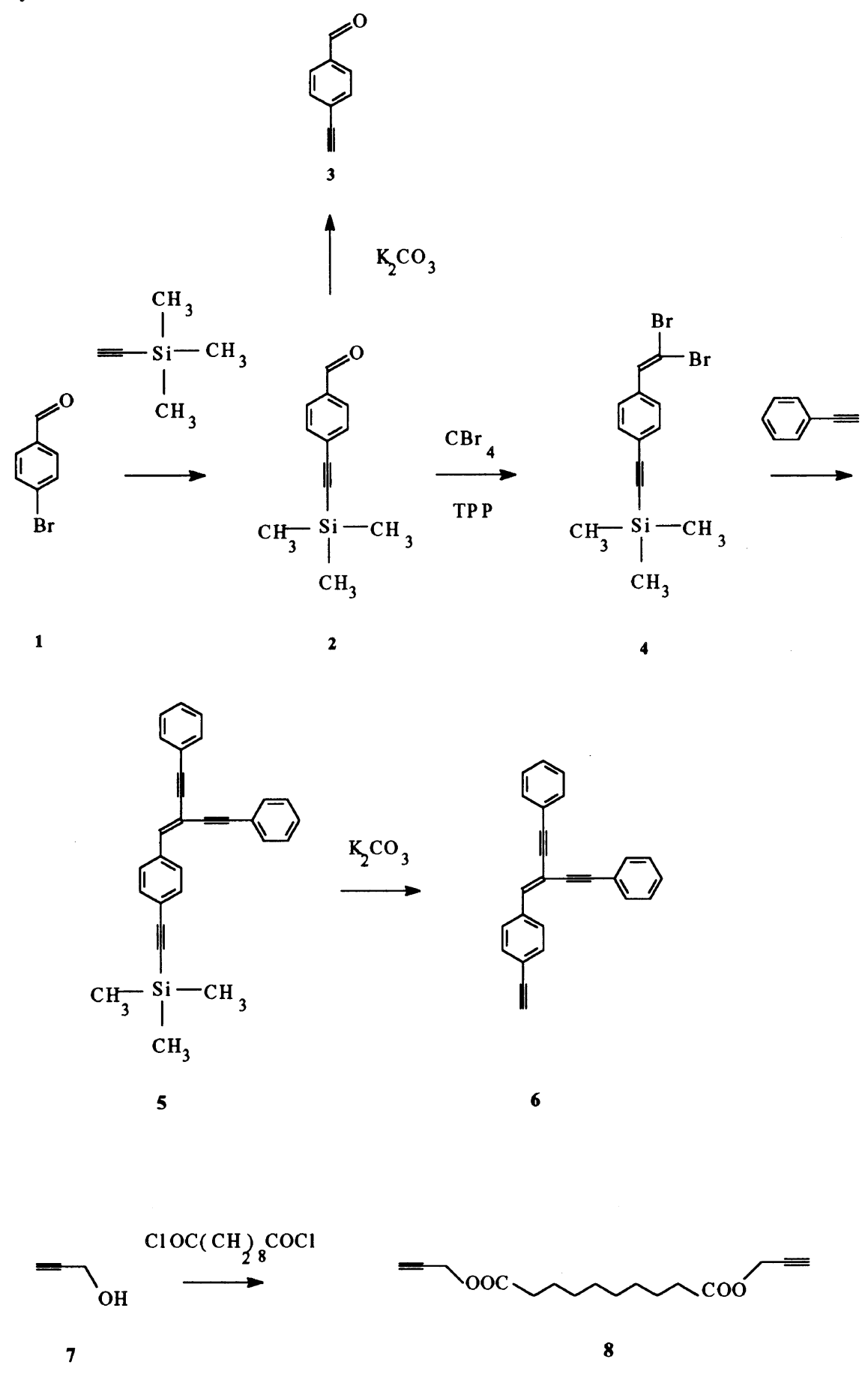

Scheme 1. (a) 
Novel Polymers Containing Discrete Conjugated Units, Produced by the Heck Reaction

Monomer Synthesis

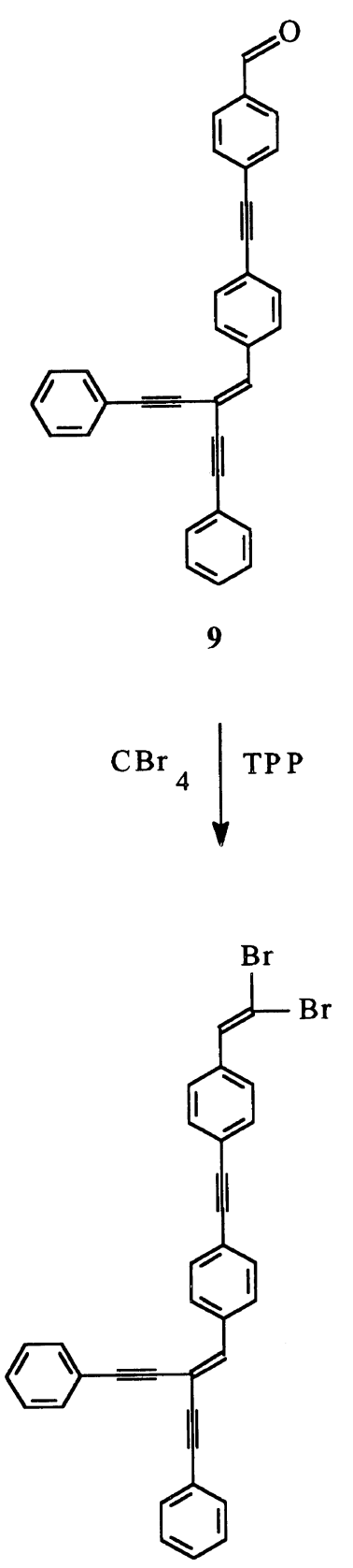

12

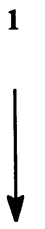

3

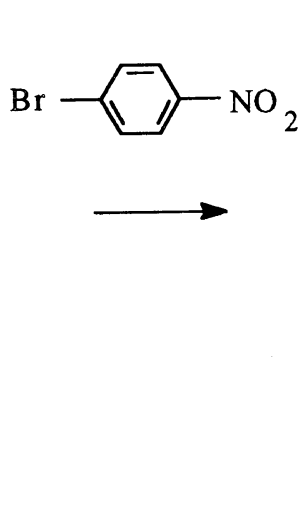

(1)

11

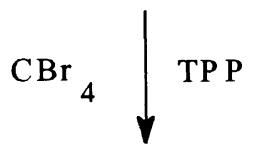<smiles>O=Cc1ccc(C#Cc2ccccc2)cc1</smiles>

10
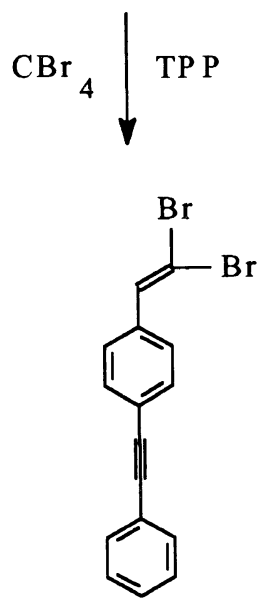

13

Scheme 1. (b) 
Polymer Synthesis
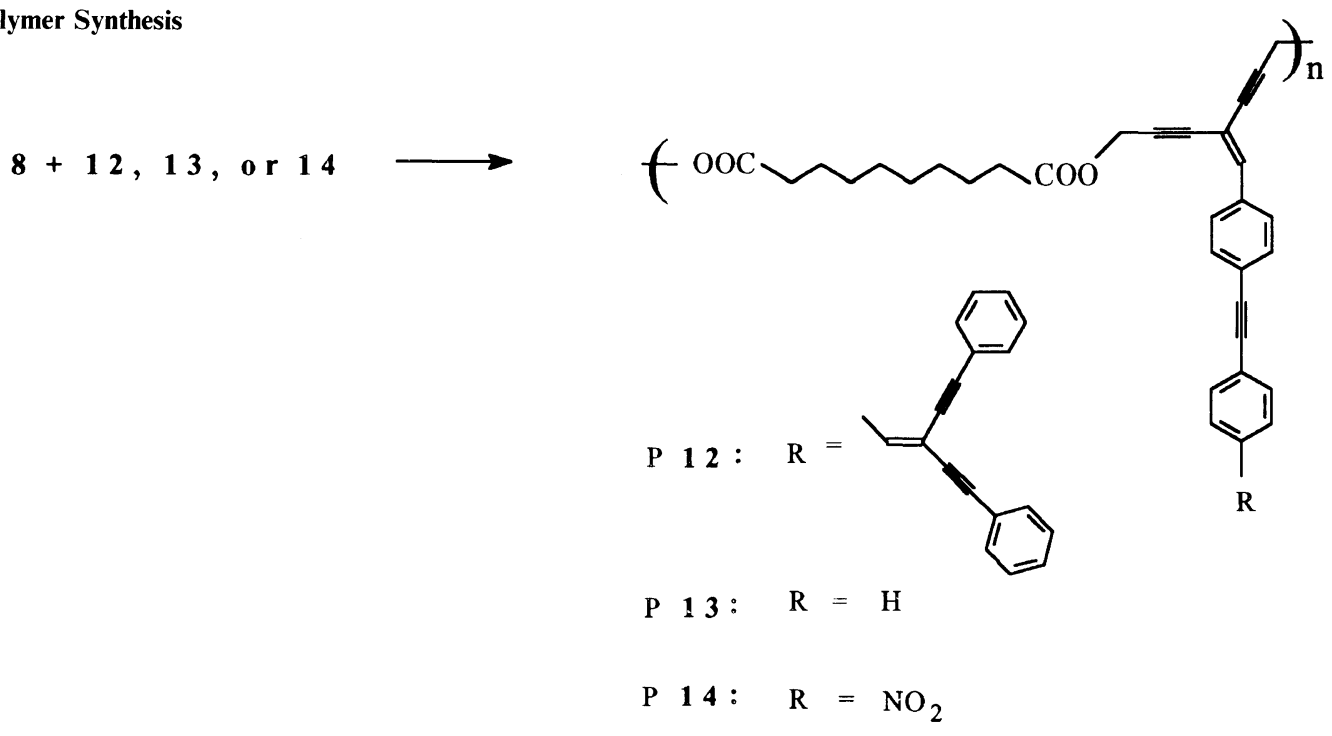

Scheme 1. (c)

vinylideneethynylenes with bisacetylenes with flexible spacer. Arylenevinyledeneethynylene groups are more conjugated than aryleneethynylene groups since the conjugations between double and triple bond is better than that between triple bond and benzene ring.

\section{EXPERIMENTAL}

\section{Materials}

Triethylamine, methylene chloride, and dioxane all from Aldrich, were distilled over $\mathrm{CaH}_{2}$ and stored under nitrogen. Other reagents (Aldrich) were used as received.

\section{Monomer Synthesis}

The synthesis of the monomers and the polymers is shown in Scheme $1(\mathrm{a}, \mathrm{b}, \mathrm{c})$.

$\beta, \beta$-Di(phenylethynyl)-4-ethynyl styrene (6), 4-ethynylbenzaldehyde (3), and dipropargyl sebacate (8) were prepared according to the literature. $^{8-10}$

\section{4-Formyl-4'-(di(phenylethynyl) vinyl $)$ diphenyl- acetylene (9)}

A solution containing pyridine $(200 \mathrm{ml})$, triethylamine $(200 \mathrm{ml})$, 4-bromobenzaldehyde
(1) $\quad\left(7.7 \mathrm{~g}, \quad 4.2 \times 10^{-2} \mathrm{~mol}\right), \quad \beta, \beta$-Di(phenylethynyl)-4-ethynyl styrene (6) (13.6 g (4.2 $\times$ $\left.10^{-2} \mathrm{~mol}\right)$, triphenylphosphine (TPP) $(0.7 \mathrm{~g})$, $\mathrm{CuI}(0.2 \mathrm{~g})$, and $\mathrm{PdCl}_{2}[(\mathrm{TPP})]_{2}$ was refluxed for 6 hours under nitrogen flow. The ammonium salt precipitated was filtered off and washed with hot benzene. The solvents were evaporated under vacuum, and the residue was washed with diluted $\mathrm{HCl}$, water, the dried under vacuum and chromatographed on $\mathrm{SiO}_{2}$ (hexane/benzene). Yield $63 \% . \quad T_{\mathrm{m}}=139$ $141^{\circ} \mathrm{C}$. IR $\left(\mathrm{cm}^{-1}\right) 3080$ (C-H, arom), 2210$2180(\mathrm{C} \equiv \mathrm{C}), 1697(\mathrm{C}=\mathrm{O}$, aldehyde $)$, and 1597 $\left(\mathrm{C}=\mathrm{C}\right.$, arom). ${ }^{1} \mathrm{H}$ NMR $\left(\mathrm{CDCl}_{3}\right) 7.14(\mathrm{~s}, 1 \mathrm{H}$, $\left.-\mathrm{HC}=\mathrm{C}-(-\mathrm{C} \equiv \mathrm{C}-\mathrm{Ph})_{2}\right), \quad 7.34-7.39, \quad 7.50-$ 7.58 (m, 12H, arom.), 7.67 (d, 2H, meta to $-\mathrm{HC}=\mathrm{O}), 7.85(\mathrm{~d}, 2 \mathrm{H}$, ortho to $-\mathrm{HC}=\mathrm{O})$, $7.94-7.97$ (d, 2H, arom.), 10.02 (s, 1H, $\mathrm{HC}=\mathrm{O}) .{ }^{13} \mathrm{C} \mathrm{NMR}\left(\mathrm{CDCl}_{3}\right) 86.93,89.17$, 89.26, 90.29, 93.52, $95.56 \quad(\mathrm{C} \equiv \mathrm{C}), \quad 104.7$ $\left((\mathrm{Ph}-\mathrm{C} \equiv \mathrm{C})_{2}-\mathrm{C}=\right), 122.8,122.9123 .0,128.4$, $128.5,128.6,129.0,129.5,129.6,131.7,131.8$, 131.81, 132.2, 132.5, 135.6 (all ring atoms), $136.4\left(\mathrm{Br}_{2} \mathrm{C}=\mathrm{C}-\mathrm{Ar}\right), 141.9 \quad(-\mathrm{HC}=\mathrm{C}-(\mathrm{C} \equiv$ $\left.\mathrm{C}-\mathrm{Ph})_{2}\right)$, and $191.3(-\mathrm{HC}=\mathrm{O})$. 
4-( $\beta, \beta$-Dibromovinyl $)-4^{\prime}-($ di(phenylethynyl $)-$ vinyl)diphenylacetylene (12)

To a solution of TPP $\left(15.5 \mathrm{~g}, 6 \times 10^{-2} \mathrm{~mol}\right)$ in $250 \mathrm{ml}$ dry $\mathrm{CH}_{2} \mathrm{Cl}_{2}, \mathrm{CBr}_{4}\left(10 \mathrm{~g}, 3 \times 10^{-2}\right.$ mol) was added dropwise during $10 \mathrm{~min}$ under nitrogen. The orange solution formed was stirred for $20 \mathrm{~min}$ and 4-formyl-4'-(di(phenylethynyl)vinyl)diphenylacetylene (9) (12.86 g, $3 \times 10^{-2} \mathrm{~mol}$ ) in $200 \mathrm{ml}$ of $\mathrm{CH}_{2} \mathrm{Cl}_{2}$ was added to the solution, and the reaction mixture was stirred for 6 hours at room temperature under nitrogen flow. The solvent was evaporated and the residue extracted with hot hexane. The hexane was evaporated and the crude product was chromatographed on $\mathrm{SiO}_{2}$ (hexane). Yield $43 \% . T_{\mathrm{m}}=138-141^{\circ} \mathrm{C}$. IR $\left(\mathrm{cm}^{-1}\right)$ 3050 (C-H, arom.) $2200(\mathrm{C} \equiv \mathrm{C})$, and 1597 $\left(\mathrm{C}=\mathrm{C}\right.$, arom.). ${ }^{1} \mathrm{H}$ NMR $\left(\mathrm{CDCl}_{3}\right) 7.14(\mathrm{~s}, 1 \mathrm{H}$, $\left.-\mathrm{HC}=\mathrm{C}-\mathrm{C} \equiv \mathrm{C}-\mathrm{Ph})_{2}\right), 7.46(\mathrm{~s}, 1 \mathrm{H},-\mathrm{HC}=$ $\mathrm{CBr}_{2}$ ), 7.32-7.39, 7.47-7.57 (m, 12H, arom.), and 7.92-7.95 (d, 2H, arom.). ${ }^{13} \mathrm{C}$ NMR $\left(\mathrm{CDCl}_{3}\right)$ 86.94, 89.06, 89.18, 90.45, 90.91, 95.41 $(\mathrm{C} \equiv \mathrm{C}), 91.00\left(\mathrm{Br}_{2} \mathrm{C}=\right) 104.2\left((\mathrm{Ph}-\mathrm{C} \equiv \mathrm{C}-)_{2}-\right.$ $\mathbf{C}=), 122.7,122.8,123.3,123.6,126.6,128.3$, 128.4, 128.5, 128.6, 128.92, 128.9, 131.6, 131.7, 131.74, 135.1, 135.8 (all ring aroms), 136.2 $\left(\mathrm{Br}_{2} \mathrm{C}=\mathrm{C}-\mathrm{Ar}\right)$, and $142.0 \quad(-\mathrm{HC}=\mathrm{C}-(\mathrm{C} \equiv$ C-Ph $\left.)_{2}\right)$. Elemental analysis. $\left(\mathrm{C}_{34} \mathrm{H}_{20} \mathrm{Br}_{2}\right)$ Calcd: C, $69.41 \%$; H, 3.43\%. Found: C, $69.21 \%$; H, $3.41 \%$.

\section{4-(Formyl)diphenylacetylene (10)}

A solution containing 4-bromobenzaldehyde (1) $(24.5 \mathrm{~g}, 0.13 \mathrm{~mol})$, phenylacetylene $(16.4 \mathrm{~g}$, $0.13 \mathrm{~mol})$, TPP $(1 \mathrm{~g}), \quad \mathrm{CuI}(0.3 \mathrm{~g}), \mathrm{PdCl}_{2}$ $\left[(\mathrm{TPP})_{2}\right](0.4 \mathrm{~g})$ and $300 \mathrm{ml}$ of triethylamine, was refluxed for 4 hours. The ammonium salt precipitated was filtered off and washed with hot benzene. The solvents were evaporated under vacuum and the residue was washed with dilute $\mathrm{HCl}$ and water and then dried under vacuum. The product was crystallized from a hexane/benzene mixture. Yield $54 \%, T_{\mathrm{m}}=$ $100-102^{\circ} \mathrm{C}$ (lit. $102^{\circ} \mathrm{C}^{11}$ ).
4-( $\beta, \beta$-Dibromovinyl)diphenylacetylene (13)

To a solution of TPP $\left(25.4 \mathrm{~g}, 9.7 \times 10^{-2} \mathrm{~mol}\right)$ in $250 \mathrm{ml}$ of dry $\mathrm{CH}_{2} \mathrm{Cl}_{2}, \mathrm{CBr}_{4}(16 \mathrm{~g}, 4.85 \times$ $10^{-2} \mathrm{~mol}$ ) was added dropwise during $10 \mathrm{~min}$ under nitrogen. The orange solution formed was stirred for $20 \mathrm{~min}$ and 4-formyldiphenylacetylene (10) $\left(10 \mathrm{~g}, 4.85 \times 10^{-2} \mathrm{~mol}\right)$ in $200 \mathrm{ml}$ of $\mathrm{CH}_{2} \mathrm{Cl}_{2}$ was added to the solution and the reaction mixture was stirred for 6 hours at room temperature under nitrogen flow. The solvent was evaporated and the residue was extracted with hot hexane. Hexane was evaporated and the crude product was chromatographed on $\mathrm{SiO}_{2}$ (hexane). Yield $48 \% . T_{\mathrm{m}}=$ $73^{\circ} \mathrm{C}$. IR ( $\left.\mathrm{cm}^{-1}\right) 3040$ (C-H, arom.) 2210 $(\mathrm{C} \equiv \mathrm{C})$, and $1601\left(\mathrm{C}=\mathrm{C}\right.$, arom.). ${ }^{1} \mathrm{H}$ NMR $\left(\mathrm{CDCl}_{3}\right) \quad 7.30-7.40, \quad 7.50-7.60 \quad(\mathrm{~m}, 9 \mathrm{H}$, arom.), and $7.46\left(\mathrm{~s}, \quad 1 \mathrm{H}, \quad-\mathbf{H C}=\mathrm{CBr}_{2}\right)$. ${ }^{13} \mathrm{C}$ NMR $\left(\mathrm{CDCl}_{3}\right)$ 89.10, 90.35 $(\mathrm{C} \equiv \mathrm{C})$, $90.78\left(\mathrm{Br}_{2} \mathrm{C}=\right), 123.5,126.6,128.3,128.4$, 128.5, 128.6, 131.55, 131.63 (all ring carbons), and 136.2 (=C-Ar). Elemental analysis: $\left(\mathrm{C}_{16} \mathrm{H}_{10} \mathrm{Br}_{2}\right)$ Calcd: C, 53.08\%; H, 2.78. Found: C, $53.77 \%$; H, $2.81 \%$.

\section{4-Formyl-4'-nitrodiphenylacetylene (11)}

A solution containing 4-bromonitrobenzene $\left(7.2 \mathrm{~g}, \quad 3.57 \times 10^{-2}\right), \quad$ 4-ethynylbenzaldehyde $\left(4.66 \mathrm{~g}, \quad 3.57 \times 10^{-2} \mathrm{~mol}\right)$, TPP $(0.3 \mathrm{~g}, \quad \mathrm{CuI}$ $(0.1 \mathrm{~g}), \mathrm{PdCl}_{2}\left[(\mathrm{TPP})_{2}\right](0.2 \mathrm{~g}), 100 \mathrm{ml}$ of triethylamine and $100 \mathrm{ml}$ of pyridine was refluxed for 4 hours. The ammonium salt precipitated was filtered off and washed with a hot benzene. The solvents were evaporated under vacuum and the residue was washed with diluted $\mathrm{HCl}$ and water and the dried under vacuum and crystallized from ethanol. $T_{\mathrm{m}}=$ $206-207^{\circ} \mathrm{C}$. Yield $56 \%$. IR $\left(\mathrm{cm}^{-1}\right) 3040(\mathrm{C}-\mathrm{H}$, arom.), $2843(\mathrm{H}-\mathrm{C}=\mathrm{O}), 2214(\mathrm{C} \equiv \mathrm{C}), 1703$ ( $\mathrm{C}=\mathrm{C}$, aldehyde), $1601(\mathrm{C}=\mathrm{C}$, arom.), 1533, and $1340\left(\mathrm{NO}_{2}\right) .{ }^{1} \mathrm{H}$ NMR $\left(\mathrm{CDCl}_{3}\right) 7.63(\mathrm{~d}$, $2 \mathrm{H}($ meta to $-\mathrm{HC}=\mathrm{O})), 7.65(\mathrm{~d}, 2 \mathrm{H}$ (meta to $\left.\mathrm{NO}_{2}\right)$ ), $7.83(\mathrm{~d}, 2 \mathrm{H}$ (ortho to $-\mathrm{HC}=\mathrm{O})$ )) 8.18 (d, $2 \mathrm{H}$ (ortho to $\mathrm{NO}_{2}$ )), and $9.98(\mathrm{~s}, 1 \mathrm{H}$, $\mathrm{HC}=\mathrm{O}),{ }^{13} \mathrm{C} \mathrm{NMR}\left(\mathrm{CDCl}_{3}\right) 90.94,93.56$ $(\mathrm{C}=\mathrm{C}), 123.43,123.75,128.24,129.37,129.64$, 
$132.41,132.55,136.22$ (all ring atoms), and $191.15(-\mathrm{HC}=\mathrm{O})$.

4-( $\beta, \beta$-Dibromovinyl)-4'-nitrodiphenylacetylene (14)

To a solution of TPP $\left(4.4 \mathrm{~g}, 1.7 \times 10^{-2} \mathrm{~mol}\right)$ in $50 \mathrm{ml}$ of dry $\mathrm{CH}_{2} \mathrm{Cl}_{2}, \mathrm{CBr}_{4}(2.83 \mathrm{~g}, 8.5 \times$ $10^{-3} \mathrm{~mol}$ ) was added dropwise during $10 \mathrm{~min}$ under nitrogen. The orange solution formed was stirred for $20 \mathrm{~min}$ and 4-formyl-4'-nitrodiphenylacetylene (11) $\left(2.14 \mathrm{~g}, 8.5 \times 10^{-3} \mathrm{~mol}\right)$ in $50 \mathrm{ml}$ of $\mathrm{CH}_{2} \mathrm{Cl}_{2}$ chloride was added to the solution and the reaction mixture was stirred for 6 hours at room temperature under nitrogen flow. The solvent was evaporated and the residue was extracted with hot hexane. Hexane was evaporated and the crude product was chromatographed on $\mathrm{SiO}_{2}$ (hexane). Yield $57 \% . T_{\mathrm{m}}=160-163^{\circ} \mathrm{C}$. IR $\left(\mathrm{cm}^{-1}\right) 3040(\mathrm{C}-\mathrm{H}$, arom.) $2210(\mathrm{C} \equiv \mathrm{C}), 1591(\mathrm{C}=\mathrm{C}$, arom.), and $1336\left(-\mathrm{NO}_{2}\right) .{ }^{1} \mathrm{H}$ NMR $\left(\mathrm{CDCl}_{3}\right), 7.49(\mathrm{~s}, 1 \mathrm{H}$, $\left.-\mathrm{HC}=\mathrm{CBr}_{2}\right), \quad 7.56-7.59(\mathrm{~m}, 4 \mathrm{H}$, arom. $)$, $7.66-7.68\left(\mathrm{~m}, 2 \mathrm{H}\right.$, meta to $\left.\mathrm{NO}_{2}\right)$, and 8.20 $8.25\left(\mathrm{~m}, 2 \mathrm{H}\right.$, ortho to $\left.\mathrm{NO}_{2}\right) .{ }^{13} \mathrm{C} \mathrm{NMR}$ $\left(\mathrm{CDCl}_{3}\right), 88.72,94.25(\mathrm{C} \equiv \mathrm{C}), 91.01\left(\mathrm{Br}_{2} \mathrm{C}=\right)$, 122.2, 123.7, 128.5, 129.9, 131.8, 132.3 (all ring carbons), $136.0(=\mathrm{C}-\mathrm{Ph})$, and 147.1 ( $\mathrm{C}-$ $\left.\mathrm{NO}_{2}\right)$. Elemental analysis: $\left(\mathrm{C}_{16} \mathrm{H}_{9} \mathrm{NO}_{2} \mathrm{Br}_{2}\right)$ Calcd: C, $47.21 \%$; H, 2.23\%; N, 3.44\%. Found: C, $47.89 \%$; H, $2.21 \%$; N, 3.45\%.

\section{Polymerization}

Polymers P12, P13, and P14 were prepared as follows: $1 \times 10^{-2} \mathrm{~mol}$ of the monomer 12 , 13 , or 14 and $1 \times 10^{-2}$ mol of monomer 8 were dissolved in a mixture of $20 \mathrm{ml}$ of dioxane and $20 \mathrm{ml}$ of triethylamine. Nitrogen was bubbled through the solution for $20 \mathrm{~min}$, then catalyzer was added $(0.2 \mathrm{~g}$, of TTP, $0.1 \mathrm{~g}$ of $\mathrm{CuI}$, aand $0.15 \mathrm{~g}$ of $\left.\mathrm{PdCl}_{2}\left[(\mathrm{TTP})_{2}\right]\right)$ and the reaction mixture was refluxed under nitrogen flow for 24 hours. In all cases, the polymers formed were soluble in the reaction mixture during polymerization. The ammonium salt precipitated during the polymerization was filtered off, and washed with dioxane. The mother
Table I. Elemental analysis data of the polymers P12, P13, and P14

\begin{tabular}{|c|c|c|c|c|c|c|c|}
\hline \multirow{2}{*}{ Polymer } & \multirow{2}{*}{ Formula } & \multicolumn{3}{|c|}{ Calcd $/ \%$} & \multicolumn{3}{|c|}{ Found $/ \%$} \\
\hline & & $\mathrm{C}$ & $\mathrm{H}$ & $\mathbf{N}$ & $\mathrm{C}$ & $\mathrm{H}$ & $\mathrm{N}$ \\
\hline P12 & $\left(\mathrm{C}_{50} \mathrm{H}_{40} \mathrm{O}_{4}\right)_{n}$ & 85.2 & 5.72 & - & 84.33 & 5.81 & \\
\hline P13 & $\left(\mathrm{C}_{32} \mathrm{H}_{30} \mathrm{O}_{4}\right)_{n}$ & 80.31 & 6.32 & - & 79.91 & 6.41 & \\
\hline P14 & $\left(\mathrm{C}_{32} \mathrm{H}_{29} \mathrm{NO}_{6}\right)_{1}$ & 73.41 & 5.58 & 2.68 & 73.01 & 5.55 & 2.43 \\
\hline
\end{tabular}

liquor was concentrated under vacuum and the polymer was precipitated in methanol, which was filtered off, rinsed with water and methanol and dried under vacuum at room temperature. The elemental analysis data are presented in Table I.

\section{Measurements and Sample Preparation}

The relative molecular weight was determined using a Varian 9012 instrument at $30^{\circ} \mathrm{C}$ in THF with polystyrene standard, universal column and a flow of $1 \mathrm{ml} \mathrm{min}{ }^{-1}$. DSC was performed at a heating rate of $20^{\circ} \mathrm{Cmin}^{-1}$ under nitrogen with a du Pont 2100. FTIR-spectra were taken using a Nikolet $510 p$ spectrometer. UV-Visible spectra were taken using a Shimadzu UV-260 spectrometer in chloroform. ${ }^{1} \mathrm{H}$ NMR and ${ }^{13} \mathrm{C}$ NMR spectra were taken using a Varian spectrometer at $300 \mathrm{MHz}$ and $75.5 \mathrm{MHz}$, respectively, in $\mathrm{CDCl}_{3}$ with TMS as an internal standard. Photoluminescence was measured using a Perkin-Elmer LS-2 fluorimeter in $\mathrm{CHCl}_{3}$ solution or in solid films with exitation wavelength of $320 \mathrm{~nm}$.

\section{RESULTS AND DISCUSSION}

The polymerization was carried out in dioxane in the presence of triethylamine as a $\mathrm{HBr}$ scavenger. Dioxane is a good solvent to solubilize the Pd complex and polymers. The reaction mixture was homogeneous during polymerization to give soluble film forming polymers with observed molecular weights $\left(M_{w}\right)$ of 41000,23000 , and 18000 , for the 
polymers P12, P13, and P14, respectively, with a fairly narrow molecular weight distribution for this type of polycondensation $\left(M_{w} / M_{n}=\right.$ $1.4-1.6)$. The polymers were yellow powders soluble in common organic solvents such as tetrahydrofuran (THF), chloroform and methylene chloride. It is noteworthy that polymer P12 showed strong blue luminescence in solution and also as a film.

FT-IR spectra of the polymers P12, P13, and $\mathbf{P 1 4}$ are shown in Figure 1. All spectra showed absorption bands around 3050 and $2900 \mathrm{~cm}^{-1}$, corresponding to $\mathrm{C}-\mathrm{H}$ stretching of rigid and soft segments of the polymer chain, respectively. In the region of $\mathrm{C} \equiv \mathrm{C}$ stretches an absorption band of internal triple bonds of the main and side chain could be seen around $2200 \mathrm{~cm}^{-1}$. An intensive peak of ester carbonyl stretching appeared at $1740 \mathrm{~cm}^{-1}$. Polymer P14 showed a strong absorption band at

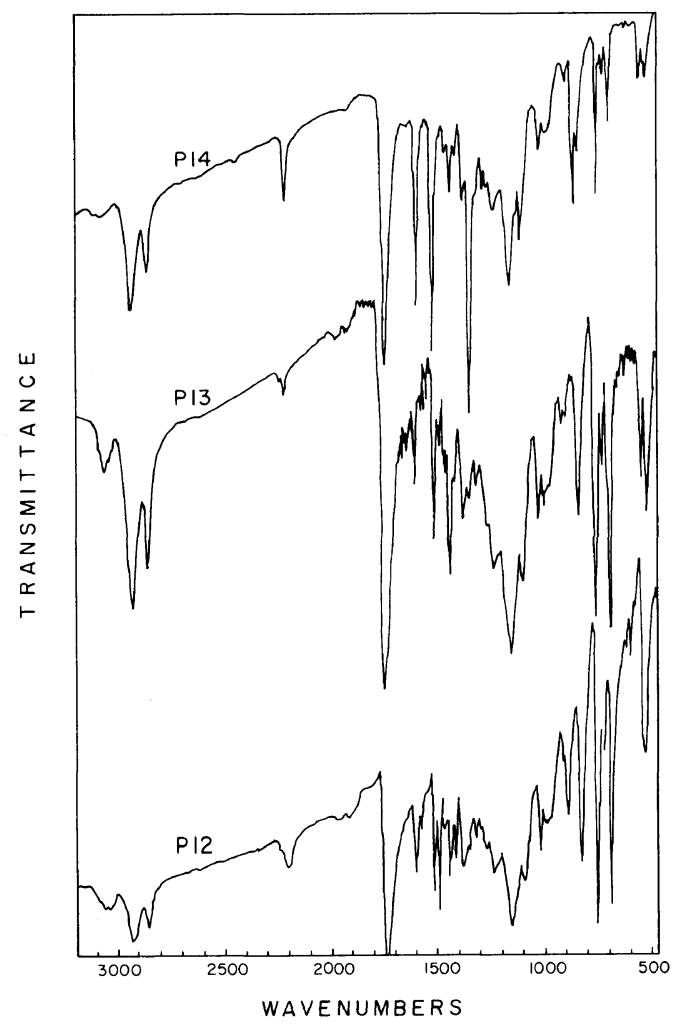

Figure 1. FTIR spectra of polymers P12, P13, and P14.
$1342 \mathrm{~cm}^{-1}$ due to the nitro group. These data agree well with the polymer structures. None of the polymers showed terminal acetylenic end groups (3300 and $2100 \mathrm{~cm}^{-1}$ ) which suggests that the polymerization was complete.

${ }^{1} \mathrm{H}$ NMR spectra of the polymers are shown in Figure 2. Apart from the signals of aromatic protons in the region of $7-8 \mathrm{ppm}$, all 3 polymers exhibited four multipletes with relative intensity of $1: 1: 1: 2$ around $4.8,2.3$, 1.6 , and $1.25 \mathrm{ppm}$, corresponding to the protons of $-\mathrm{CH}_{2}-$ of propargyl groups, methylene groups next to $\mathrm{C}=\mathrm{O}$, methylene groups$\mathrm{OC}-\mathrm{CH}_{2} \mathrm{CH}_{2}-$ and internal methylene groups of methylene spacer, respectively. In ${ }^{13} \mathrm{C}$ NMR spectra, the signals of these methylene carbons appeared at 52.00, 34.00, 29.00, and $24.8 \mathrm{ppm}$, respectively. Ester carbonyl carbons of polymers P12, P13, and P14 appeared at 173 ppm. After the polymerization, signals of the protons of dibromovinyl group $\left(-\mathrm{HC}=\mathrm{CBr}_{2}\right)$, in monomers 12, 13, and 14 around $7.45 \mathrm{ppm}$ disappeared and a new signal of protons of diethynylvinyl group $\left(-\mathrm{CH}=\mathrm{C}-(\mathrm{C} \equiv \mathrm{C})_{2}\right)$ of polymers could be clearly seen around 7.14 ppm. At the same time, the signals of the carbon atoms of dibromovinyl group $(-\mathrm{HC}-$ $\left.\mathrm{CBr}_{2}\right)$ which appeared around $91(-\mathrm{HC}=$

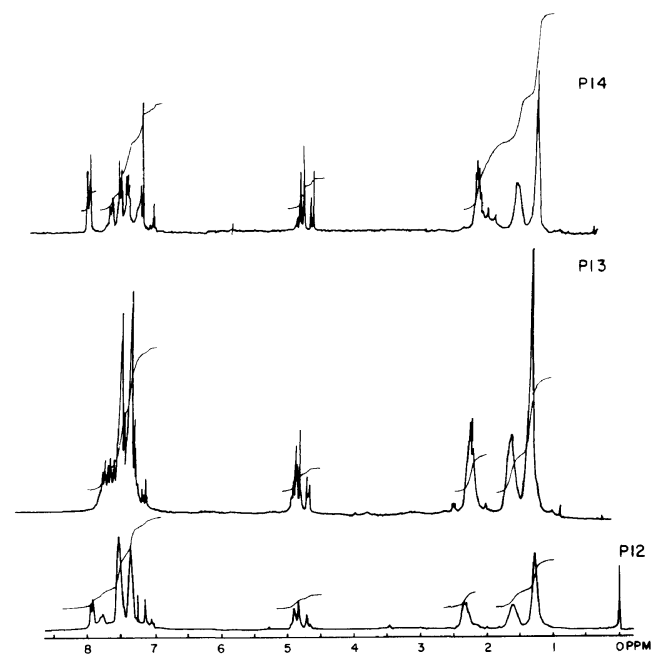

Figure 2. ${ }^{1} \mathrm{H}$ NMR spectra of polymers P12, P13, and P14. 
$\left.\mathrm{CBr}_{2}\right)$ and $136 \mathrm{ppm}\left(-\mathrm{HC}=\mathrm{CBr}_{2}\right)$, respectively, in the monomers, disappeared after the polymerization and signals of the carbon atoms of diethynylvinyl group could be detected at 104.2 and $144.3 \mathrm{ppm}$, respectively. Positions of the signals of aromatic protons in ${ }^{1} \mathrm{H}$ NMR spectra and aromatic carbons in ${ }^{13} \mathrm{C}$ NMR spectra of polymers P12, P13, and P14 coincided with those of monomers 12, 13, and 14, respectively.

UV-Visible spectra of the monomers 12, 13, 14, and corresponding polymers P12, P13, and P14 are shown in Figure 3. As can be seen the long wave absorption maximum of the monomers shifted to the long wave wavelength from monomer $12(311 \mathrm{~nm})$ to $14(380 \mathrm{~nm})$ because of expanding of the conjugation system. An additional long wave shift of long wave absorption maxima took place on polymerization. Thus, polymers P12, P13, and P14 showed long wave absorption maximum at 340,360 , and $400 \mathrm{~nm}$, respectively. This additional bathochromic shift of the long wave absorption maxima was due to further extension of the conjugated system in the polymers by the two additional ethynyl groups.

Polymer P12 exhibited strong blue luminescence in solution and in the solid state (film).

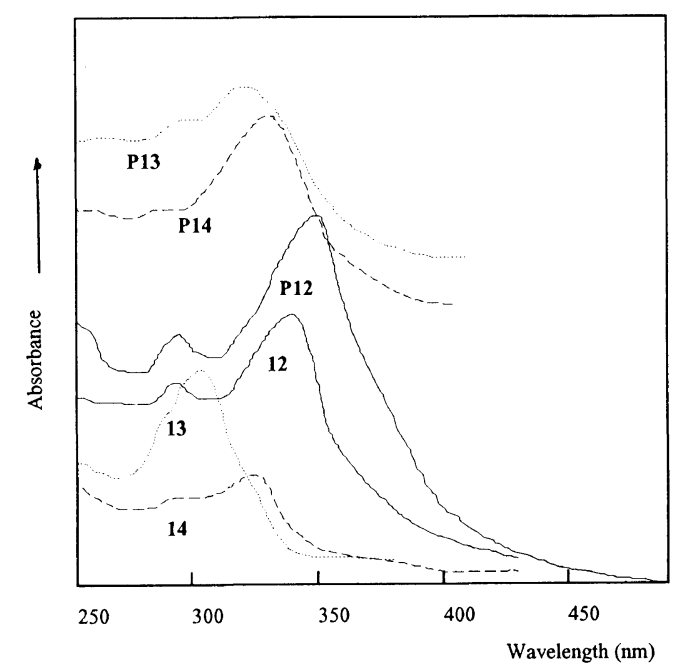

Figure 3. UV-Visible spectra of monomers 12, 13, P14, and polymers P12, P13, and P14.
The spectra of luminescence are shown in Figure 4. The spctra of both solution and film had two maxima at $380-390$ and 470 $480 \mathrm{~nm}$.

Preliminary $\left(\chi^{(3)}\right)$ of polymer films were obtained using a picosecond laser consisting of a mode locked Quantel Nd: YAG laser with frequency doubled to $532 \mathrm{~nm}$. $\left(\chi^{(3)}\right)$ Values of polymers P12, P13, and P14 were found to be of $2.7 \times 10^{-10}, 1.1 \times 10^{-10}$, and $1.6 \times 10^{-10}$ esu, respectively.

DSC and TGA thermograms of polymers P12, P13, and P14 are presented in Figures 5 and 6 , respectively. The polymers showed a glass transition around $60^{\circ} \mathrm{C}$ and an exotherm at 175,190 , and $183^{\circ} \mathrm{C}$ for polymers P12, P13, and $\mathbf{P 1 4}$, respectively. These exotherms are

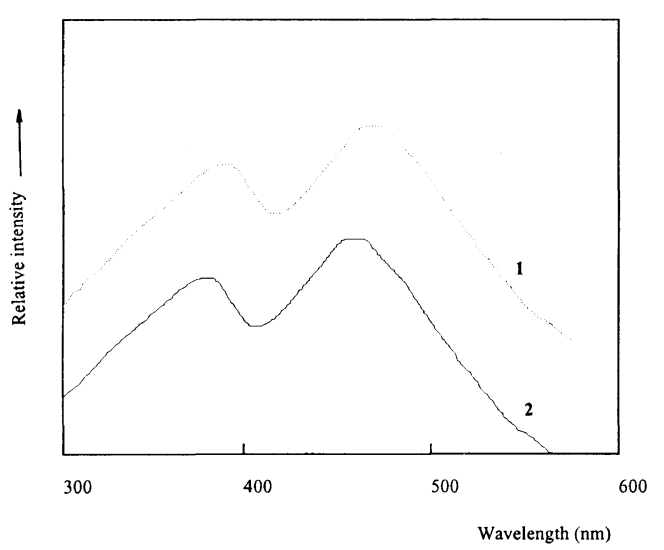

Figure 4. Luminescence spectra of polymer P12 (thin film (1), chloroform solution (2)).

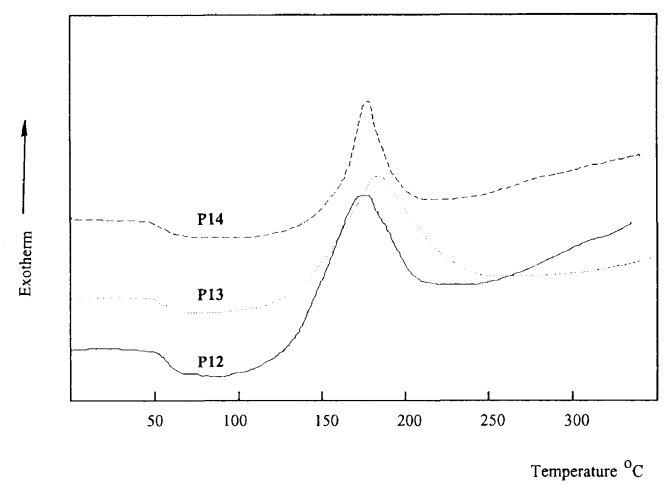

Figure 5. DSC curves of polymers P12, P13, and P14. 
Novel Polymers Containing Discrete Conjugated Units, Produced by the Heck Reaction

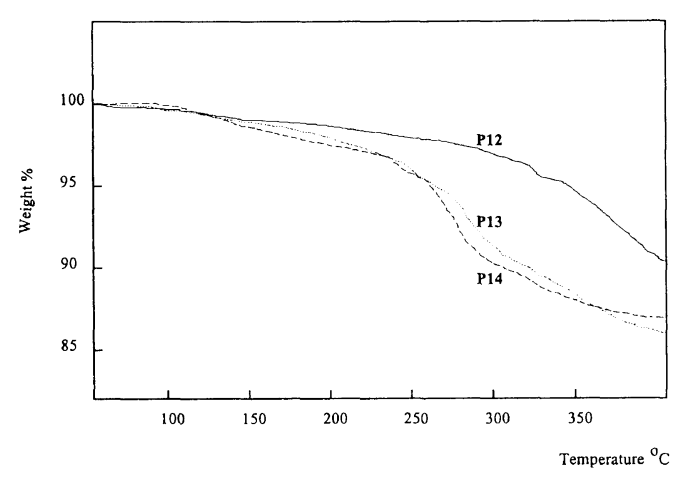

Figure 6. TGA curves of polymers P12, P13, and P14.

due to thermal cross-linking of the polymers through triple bonds based on a comparison of IR spectra of the polymers before and after heating (absorption band around $2200 \mathrm{~cm}^{-1}$ significantly decreased its intensity). According to $\mathrm{X}$ ray diffraction data the polymers were amorphous.

5\% Weight loss was observed for P12 at 340, for P13 at 240, and for $\mathbf{P 1 4}$ at $250^{\circ} \mathrm{C}$. The thermal stability of $\mathbf{P 1 2}$ was about $100^{\circ} \mathrm{C}$ higher than that of polymers P13 and P14, which can be explained by higher content of the triple bonds in the former, leading to denser and therefore a more thermostable network with thermal cross-linking.

In conclusion, novel monomers and polymers containing arylenevinylideneethynylene groups were synthesized by the Heck reaction. The polymers were amorphous and soluble in commun organic solvents. They showed $T_{\mathrm{g}}$ around $60^{\circ} \mathrm{C}$ and $5 \%$ weight loss in the region of $250-340^{\circ} \mathrm{C}$. The polymers underwent thermal cross-linking on heating to 170 $190^{\circ} \mathrm{C}$ at the expense of triple bonds. Polymer P12 showed strong blue luminescence with emission maxima around $370-380$ and 470 $480 \mathrm{~nm}$ with excitation at $320 \mathrm{~nm}$.

Acknowledgments. The authors acknowledge the financial support of CONACyT (Consejo Nacional de Ciencias y Tecnologia) under contract No. E-9406 (1994-1995). Thanks are also due to C. Vazquez and M. A. Canzeco for the accistance in termal analysis and UV-spectroscopy, respectively. The authors express their gratitude to Professor D. Rao of Physics Department of University of Massachusetts, Boston for the $\chi^{(3)}$ measurements.

\section{REFERENCES}

1. D. Chemla and J. Zuss, Ed., "Nonlinear Optical Properties of Organic Molecules and Crystal, vol. 2, Academic Press, New York, N.Y., 1987.

2. K. Sanechika, T. Yamamoto, and A. Yamamoto, Bull. Chem. Soc. Jpn., 57, 752 (1984).

3. M. Moroni, J. Le Moigne, and S. Luzzati, Macromolecules, 27, 562 (1994).

4. T. Yamamoto, W. Yamada, M. Takagi, K. Kizu, T. Maruyama, N. Ooba, S. Tomaru, T. Kurhhara, T. Kaino, and K. Kubota, Macromolecules, 27, 6620 (1994).

5. T. Yamamoto, M. Takagi, K. Kizu, T. Maruyama, K. Kubota, H. Kanbara, T. Kurihara, and T. Kaino, J. Chem. Soc., Chem. Commun., 797 (1993).

6. L. Fomina and R. Salcedo, Polymer, in press.

7. S. Fomine, A. Pineda, T. Ogawa, R. Perez, and M. Sotelo, Polym. J., 27, 712 (1995).

8. L. Fomina, H. Allier, S. Fomine, and R. Salcedo, T. Ogawa, Polym. J., 27, 591 (1995).

9. S. Fomine, S. Sanchez, and T. Ogawa, Polym. J., 27, 165 (1995).

10. W. Austin, N. Bilow, W. Kelleghan, and K. S. Y. Lau, J. Org. Chem., 46, 2280 (1981).

11. G. Drefahl and G. Plotner, Chem. Ber., 93, 990 (1960). 